\section{Nobel Prize for 1978: P. L. Kapitza}

\section{A. S. Borovik-Romanov, Moscow \\ (Institute for Physical Problems, USSR Acad. of Sciences)}

The 1978 Nobel Prize for Physics was awarded to Professor P.L. Kapitza for fundamental discoveries in the field of low temperature physics, sharing it with two American radioastronomers Arno Penzias and Robert The discoveries of Kapitza recognized by the Nobel Committee were made mainly in the late 1930's.

Peter Kapitza is one of our foremost experimentalists who has the fortune to combine the talents of a scientist with the ingenuity of an engineer. He was born in Kronstadt in 1894. In 1918 he graduated from the Petrograd Polytechnical Institute and started his research work in the physics department headed by A.F. loffe. In 1921, Kapitza was dispatched on a scientific mission to England and worked until 1932 in the Cavendish laboratory headed by Ernest Rutherford. Their relationship developed into a mutual feeling of deep affection and friendship.

Research work on the creation of strong magnetic fields was to begin with dissociated from research on radioactivity and Kapitza was the first to place a cloud chamber in a strong magnetic field and observe the bending of $\alpha$-particle tracks. His investigations of electroconductivity in metals in strong magnetic fields obliged him to conduct his experiments at low temperatures and so he moved to the purpose built laboratory in Cambridge, the Mond laboratory. He continued his work in Moscow from 1934 onwards in the Institute for Physical is the founder and the director.

As a result of Kapitza's engineering work in low temperature physics, a new refrigerator for helium liquefaction was developed and a low temperature process for the industrial production of oxygen. Before 1920, helium liquefaction was based on the Joule-Thompson effect, requiring precooling with liquid hydrogen to temperatures below $50 \mathrm{~K}$. Kapitza succeeded in eliminating the need for this first stage which was both complicated and inefficient.

In his apparatus the helium was cooled by doing work in a special gas-driven expansion piston engine, Wilson (see EN Jan/Feb (1979) p. 8). Problems of the USSR, of which he in which the gaseous helium itself provided lubrication. The first liquefier of this type with an output of $2 \mathrm{l} / \mathrm{h}$ was long used in Kapitza's laboratory, yet, it was not until the 1950's that the industrial production of helium liquefiers began. Nowadays, practically all embody the principle proposed by Kapitza, and the production capacity of some attains several hundred litres per hour.

In the field of low temperature engineering, Kapitza developed a new method for the liquefaction of air employing a low-pressure cycle and a special high-efficiency radial expansion turbine. Kapitza's turbine with its high $(80-85 \%)$ efficiencies, set the pace for the worldwide development of large modern installations for the liquefaction of air to produce oxygen using low pressure only. In the Soviet Union and other countries, powerful air-separating units working at low pressures and producing from 10000 to $100000 \mathrm{~m}^{3} / \mathrm{h}$ of oxygen are in operation and form the basis of major industrial processes.

It is significant that Kapitza's methods remain up-to-date and no new solutions have been proposed within the last 40 years.

In low temperature physics, Kapitza began a series of highly elegant experiments to study the properties of liquid helium. One result of these experiments was his discovery of the superfluidity of helium in the late 30 's. $\mathrm{He}$ showed that the viscosity of liquid helium flowing through narrow slits at temperatures below $2.19 \mathrm{~K}$ is but a fraction of the viscosity of even the most fluid liquid and is apparently simply zero; hence his designation of this state of helium as superfluid.

The anomalous behaviour of liquid helium could not be accounted for within the framework of the conventional theory of hydrodynamics of liquids. It was explained by a theory of quantum mechanics of superfluidity developed by Lev Landau in cooperation with Kapitza, that confirmed his idea of two components being present.

Kapitza's research on the properties of liquid helium is a beautiful example of the approach of a true experimental physicist to the solution of a complex problem. Reading his papers we derive an aesthetic satisfaction from following him step by step through one experiment to another, and finally to his fundamental discovery of the coexistence in helium of two fluids with totally different properties and the ability to move within one another.

In the course of these studies, he also established the following important fact: when heat is transferred from a solid to liquid helium, a temperature discontinuity, whose magnitude increases sharply with decreasing temperature, appears at the interface the so-called Kapitza jump.

Late in the 1940's, Kapitza turned his attention to a totally new range of physical problems - those involved in the creation of powerful continuous microwave generators. He succeeded in solving the complex mathematical problem of electron motion in magnetron-type microwave generators and on the basis of these calculations, he built microwave generators of a new type - the planotron and nigotron, the second of which developed a record power of $175 \mathrm{~kW}$ in continuous operation. In studying these powerful generators, Kapitza encountered an unexpected phenome-

\section{Research Associate Positions}

will be available at the University of Zurich in the following fields:

1. Amorphous semiconductors - preparation by low pressure plasma CVD and a study of their properties,

to begin in early summer 1979.

2. Interaction of low pressure plasmas with solids, to begin in autumn 1979.

Inquiries should be sent to: Institute of Inorganic Chemistry University of Zurich Attn.: PD Dr. S. Veprek Winterthurerstrasse 190 CH - 8057 Zurich, Switzerland 
non : when a helium-filled flask was placed in the beam emitted by the generator, a very bright discharge appeared in the helium and the walls of the quartz flask melted. This suggested to Kapitza that it might be possible to heat plasma to very high temperatures through the use of microwave techniques. He coupled a chamber in the form of a microwave resonator to a nigotron, and admitted various gases (helium, hydrogen, deuterium) under a pressure of 1-2 atm. Kapitza observed a filamentary discharge at the centre of the chamber (where the microwave intensity was highest). Applying various plasma diagnostic methods, he showed that the temperature of the plasma electrons in the discharge was about 1 MK. These studies, which Kapitza is still pursuing vigorously, opened a new road to the solution of the thermonuclear problem and enabled him to suggest the design of a reactor based on this principle.

Kapitza is more than a prominent scientist ; he is also a major scientific organizer. As director of the Institute for Physical Problems, a member of the Praesidium of the USSR Academy of Sciences, and the editor-in-chief of the country's leading physics journal, he devotes much effort to concrete scientific-organizational work. As in his science, he is also an innovator here, in search of the most progressive methods of administrating a mechanism as subtle as that represented by a creative scientific work-force.

Kapitza has always given much attention to the training and selection of young people who are capable of creative scientific work. He was one of the co-founders of the Moscow Physico-Technical Institute, and is the Chairman of the Coordination Council of this Institute. Kapitza himself invariably chairs the sessions of the State Examination Commission for MFTI students who have done their undergraduate work in the Institute for Physical Problems. He also reviews every examination that applicants sit for admission to graduate work and himself prepares a set of problems for each exam.

In addition, Kapitza has been a prominent social figure. All aspects of the development of human society excite him. He is a member of the Soviet National Committee of the Pugwash movement of scientists for peace and disarmament and participated actively in this movement. $\mathrm{He}$ has often taken a stand on questions of the future development of human society, especially in connection with such pressing problems as disarmament, pollution of the environment, and the ecological crisis.

\section{Council Report from Rome}

At the Rome Council meeting, where with one exception, chairmen from all the Divisions were present, the current vitality of EPS was much in evidence. Torrential rains gave little encouragement to members to stray away to study the attractions of the ancient city and a great deal of business was accomplished. Many of the delegates were fresh from the Seminar on the European Great Projects which was generally acknowledged to have been a singular success, establishing a precedent that will undoubtedly be followed up in the future. All too often in the past, different areas of physics have found themselves in competition, whereas the Seminar took place in an atmosphere of reciprocal understanding pointing the way to an intensification of collaboration in the future.

Participants in the Executive Committee meeting that preceded Council were invited to meet the President of the Italian Republic and join the EPS President in presenting the work of the Society to the political authorities of the host country. Later, members of Council had an audience of the Pope, when again the work of the Society was explained to a non-scientific authority - following the precepts of the President that physicists must make contact with the leaders of non-scientific milieux to transmit awareness of what the scientific community is trying to do.

\section{Advisory Committee Reports}

From amongst the topics presented to Council by the Advisory Committees, particular note was taken of the following :

ACAPPI: A study has been made in Sweden of the problem of closing the gap between pure and applied physics to the mutual advantage of both. Fundamental issues of general applicability were raised and Europhysics News hopes to publish a review of these in the near future.

Conference Committee: Applications for EPS approval or sponsorship are up on last year which suggests that we have not yet reached saturation. The young physicists solidarity fee levied on participants at approved conferences is still a subject of debate but until we find an alternative source of funds we have no other way of helping young people to attend the General Conferences. Not that everyone believes that this is necessarily the optimum way of using the fund but for the present no change is contemplated.

Following exchanges between the Presidents, tentative moves have been made to implement the generally expressed wish on both sides of the Atlantic for a closer contact between EPS and APS. One area of activity is the running of joint conferences and the Divisions are now studying what can most usefully be done.
Europhysics News: The President called for a closer identification of members with their journal including using it more for situations vacant advertising. As an experiment, effort will be devoted to attracting product advertising for special issues.

Physics and Education: Analysis of the study on secondary school education was nearing completion and when properly digested will be summarized in EN. The experiment at York with the workshops and lecture on Piaget philosophies was considered to have been of considerable value. The Committee was not wishing to act as a promotional front for Piaget methods but felt that a useful task had been done in exposing the principles and practice of Piaget's teaching to a wider audience.

The Committee had completed its study of the EPS Lecturer Exchange Scheme and Council was able to give the proposals its warmest approval. Details are presented on page 9. The organizers were urged to introduce the scheme with all possible speed in order to make sure that several lecturers were already in post by $\mathrm{Au}$ tumn 1980. Council members in their turn were asked to give wide publicity to the Scheme - a stricture that applies equally to the readers of $E u$ rophysics News.

Publications Committee: Revision of the Europhysics Style Manual has now been completed and will be published in the September issue of Europhysics News together with an abridged version of the ICSU AB classification. 